\title{
PLAYING EDUCATIONAL MATH GAMES AT HOME: THE MONKEY TALES CASE
}

\author{
Jan Derboven, Bieke Zaman, David Geerts, Dirk De Grooff \\ Meaningful Interactions Lab, KU Leuven-iMinds \\ Parkstraat 45 bus 3605, 3000 Leuven (B) \\ firstname.lastname@kuleuven.be
}

Entertainment Computing (2016), doi:10.1016/j.entcom.2016.05.004

\section{HIGHLIGHTS}

We study the appropriation of the educational game Monkey Tales at children's homes.

Players use various tactics to make educational game fit their own needs.

Player tactics can comply with, or resist the game's implied behaviour.

The balance between game aspects and educational content is emergent, not fixed.

\begin{abstract}
In research on educational games, the majority of studies have been executed in controlled school settings: the home as a context in which educational games are played, is still underexplored. However, the home context is becoming more important, as children are increasingly encouraged or even required to engage with learning content at home through educational games. In this article, we describe a study of Monkey Tales, an educational math game targeted at primary school children. Using a combination of a multimodal game analysis and a six-month user study with eight children aged 10 to 11 and their families, we provide a detailed account of how players interpret and appropriate Monkey Tales at home. We investigate to what extent players develop tactics to appropriate the game to suit their personal interests. The study showed that in the home context, respondents used various tactics to avoid educational content. We describe the implications of these appropriation tactics for the generalizability of effectivity research, and for the design of educational games.
\end{abstract}

Keywords: educational games, home context, appropriation, multimodality 


\section{INTRODUCTION}

Video games are no longer designed for entertainment only: nowadays, numerous games target goals that reach far beyond mere enjoyment. The diversity of educational and serious games - games used for purposes beyond entertainment shows that many areas can benefit from the engaging experiences that video games offer, including educational [14] and therapeutic [32] contexts. As the popularity of video games for learning purposes has increased over the past years, research on educational games has become more extensive. Numerous aspects of educational games have been researched and evaluated. Several game design and evaluation frameworks have been created [42][59] and effects on specific aspects such as student motivation [43], learning effectiveness [27] and teacher adoption [7] have been researched. The majority of evaluative studies of educational math games have been executed within controlled settings, typically in dedicated game sessions in school classrooms [9][45]. Other contexts, such as the home context, have been underexplored [44]. Where the experimental design does involve playing math games in the home context, this context is bracketed, with evaluations based on a comparative study of a pre- and posttest [8]. Nevertheless, the home context is becoming increasingly important, as children are increasingly encouraged or even required to engage with learning content at home through educational games.

In this article, we complement existing research by presenting an in-depth, qualitative study of children's play and learning practices while playing an educational game in the home context. Through a multimodal game analysis and a longitudinal user study, we will focus on the lessons learned from one particular case study: the math game Monkey Tales. Using this game as a case study, we will illustrate the varied practices of children playing educational games at home. Furthermore, we want to identify the impact of game elements on playing behaviour, and, especially, relate unexpected playing behaviour to the influence of game characteristics and affordances, as well as to the playing context. In sum, we tackle the wider question of the relation between educational games and the home context based on the specific Monkey Tales case study.

We combine insight into Monkey Tales' characteristics and affordances based on a multimodal analysis, with insights in contextualized player behaviour based on user research. Based on these insights, we will show how players develop tactics that oppose or subvert the player behaviour implied in the game when the game content does not match the players' needs. An analysis of these player tactics allows us to formulate recommendations for the evaluation and design of educational games. Concerning evaluation, we suggest that taking into account contextualized playing practices is crucial for a good understanding and evaluation of educational games. Concerning design, we focus on how to cope with the balance between game elements and educational content.

\section{EDUCATIONAL MATH GAMES AND THE HOME CONTEXT}

Recently, math games, as a specific subdomain of STEM (Science, Technology, Engineering and Mathematics) educational games, have received considerable research attention. Previous work has been reported on the design and development of educational math games [2], design principles for math games [12][13] and the 
evaluation of various aspects of educational games. Typically, these evaluative studies use classrooms as a controlled research environment. For instance, Chang et al. [9] studied students' engagement in reaction to a fractions app on iPod Touch, paying special attention to student gender. Pareto and colleagues [45] investigated students' mathematics understanding, attitude and self-efficacy after playing the Teachable Agent Arithmetic Game, while Katmada and colleagues [36] focused on the usability of the Volcanic Riddles game. Castellar and colleagues [8] studied cognitive abilities and math performance in a longer-term study in which students played the commercial math game Monkey Tales at home.

While evaluative studies have focused on aspects such as usability, learning effects, and engagement, research into educational games in general, and educational math games in specific, has not looked in detail at the effects of the context in which games are played. Most studies are executed in controlled settings, with play sessions set in formal learning contexts, supervised either by researchers or teachers: classrooms are the settings that are researched most often [28]. However, educational games are increasingly used outside the classroom, in informal settings. Several manufacturers have created educational games targeted at children, to let them practice skills like spelling (Nintendo: Scribblenauts) or math (Die Keure/Larian Studios: Monkey Tales) at home. This use of educational games outside the class context warrants additional research into the influence of a less controlled home environment on the perception of and experience with educational games.

To date, there is little research studying in detail the way children play educational math games at home. The home context, being less rigidly structured and supervised than formal classroom contexts, can be expected to have an influence on how educational games are perceived and appropriated. At home, parents do not necessarily specify rigid rules, a planned pedagogy or a specific time frame for playing educational games [44]: the context is different in terms of supervision, and social norms and rules. Our overarching research question, then, concentrates on the influence of the home context: we study the role of a specific math game in the home context as a case study in order to tackle the wider question of the relation between educational games and the home context. Specifically, we investigate how children's contextualized play and learning practices and experiences are shaped, when they play Monkey Tales at home. We will formulate an answer to this question by focusing on the interplay between the game, the players, and their context in a study of game appropriation, exposing the consequences of game design choices in the home context.

\section{EDUCATIONAL GAME APPROPRIATION: A MULTIMODAL AND ETHNOGRAPHIC APPROACH}

Appropriation is a well-known concept in HCI (Human-Computer Interaction): although interactive technologies are always designed to serve specific purposes, these technologies, including games [42], are not always used as their designers intended. Technology use is not a matter of passive reception: users actively construct and impose new meanings on the technologies they use. The creation of these new technology-related practices is often referred to as appropriation of technology although similar concepts such as domestication or interpretation are also used [47]. Previous research has focused on various technological, individual and social 
characteristics that underlie technology appropriation. For instance, the Adaptive Structuration Theory [19] focuses on the relation in decision support systems between the structural features of an application, and the related organizational structures. Dourish [22] identifies several aspects of appropriation, including both technological (e.g., flexibility) and social characteristics (e.g., community), while Salovaara [47] focuses on individual cognitive aspects underlying appropriation.

In this study, we will rely on multimodality as the overarching theoretical and methodological framework for investigating the complex relations between technology, users, and context. Multimodality is a specific interdisciplinary approach based on social semiotics, which considers communication and representation to be "more than language, and attends systematically to the social interpretation of a range of forms of making meaning" [34]. Multimodality does not study language or other sign systems in isolation: in social semiotics, "social structures and processes, messages and meanings [are] the proper standpoint from which to attempt the analysis of meaning systems" [31]. This focus on the social context in the production of meaning makes social semiotic theory an appropriate lens to study educational game appropriation in the home context, accounting for the interplay between the characteristics of the game on the one hand, and the contextualized use practices on the other. We frame this relationship as a relation between design strategies and user tactics (a distinction based on De Certeau [16] and Dourish [24] - see Figure 1). This analytic approach allows us to investigate children's contextualized play and learning practices when playing Monkey Tales at home by answering the following, more specific research questions (RQs):

RQ1: How does the game Monkey Tales guide player behaviour through the use of design strategies?

RQ2: Which (individual and social) user tactics are used to appropriate Monkey Tales?

RQ3: How are user tactics related to specific design strategies used in Monkey Tales?

When researching how Monkey Tales guides player behaviour (RQ1), we focus on design strategies: the strategies used by designers of interactive technology to embed their view of the users and their goals into the application. Designers create interactive applications with very specific goals in mind (Hassenzahl [30] has called this the 'intended product character'). They use specific strategies to realize their intentions to suggest or even impose specific interactions on the users. An analysis of these design strategies can uncover in detail how the gaming experience is guided by promoting and discouraging specific behaviour [38]. From the perspective of multimodal theory, all communication consists of a number of distinct 'modes': '"channel[s]" of representation or communication' (such as writing, image, sound) that collaborate in communicating messages [34]. In games, modes that contribute to the central game message include visual design, music, etc. Analyzing how this central message is built in different modes, and how design strategies are embedded in these modes can lead to insights on how the technology shapes its ideal 'model user' (based on Umberto Eco's model reader [25] - see also [17] and Aarseth's [1] implied player). Through its design strategies, the system 'creates' a model user that complies with the interaction implied in the system. 
RQ2 assumes that actual users are not model users. The design strategies embedded in Monkey Tales become a potential for interactivity for the actual players. As people actively impose new meanings on the technologies they use, they realize (part of) that potential in their own, personal way, creating what Hassenzahl [30] has called the 'apparent product character'. We define user tactics as these ways in which users actively impose new meanings, and appropriate the technology based on the technology characteristics, on personal characteristics (prior knowledge and experiences), and the social situation, rules and norms. Ethnographically inspired user research [55][6] can help us to understand how the nature of social rules surrounding play (e.g., who makes the rules, and how strict are they - see [57]), and users' individual interest can lead to a variety of appropriations.

Combining ethnography and semiotics is not new in itself [39]: the combination has been explored since the 1980s, for instance in literacy studies [21]. In our study, the combination is useful to better understand the interplay between design strategies, user tactics and context of use. This addresses our last research question, RQ3. Relating design strategies to user tactics will reveal to what extent an educational game can actually guide player behaviour. It will show how users, in their context, develop tactics in relation to specific design strategies.

The answers to these three research questions provide an answer to the overarching research question introduced in Section 2: what are children's contextualized play and learning practices and experiences when playing Monkey Tales at home. As different educational games use different (combinations of) design strategies to structure the game, the answer to the case study-specific research questions cannot be extended towards other educational games unproblematically. However, the analysis of the case study does offer us an insight into the types of practices children develop in the home context, and whether they develop specific appropriation tactics in response to the game's design strategies. Based on an analysis of the relation between design strategies and types of user tactics, we identify implications for the design and evaluation of future educational games. In other words, we use the results of this specific case study to open up a broader discussion on the effective use of design strategies in educational games, and on the importance of contextual factors in the evaluation of educational games.

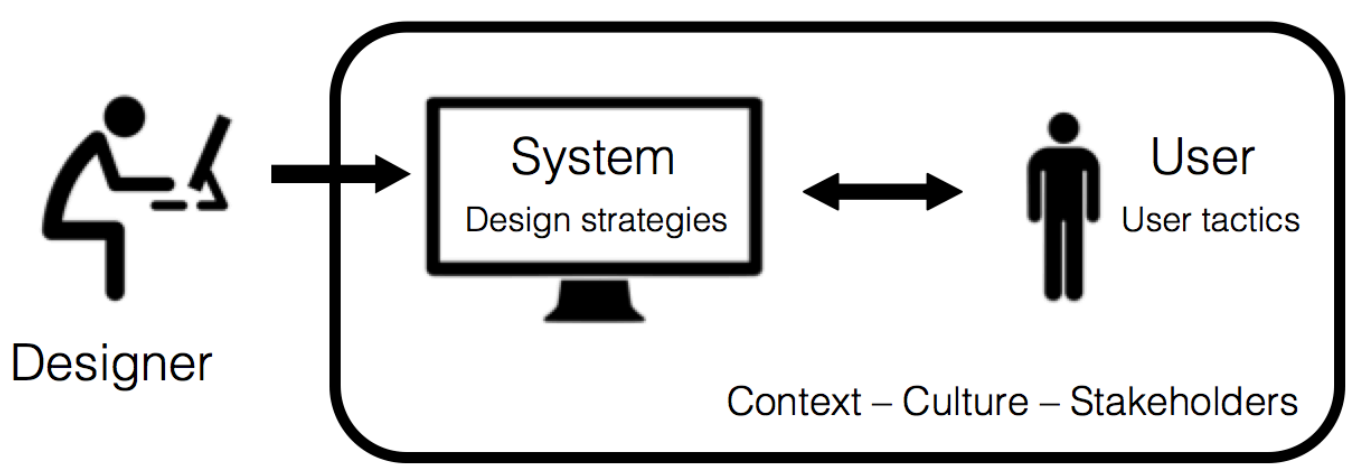

Figure 1: Interaction between design strategies embedded in interactive technology, and the users' contextualized appropriation tactics. 


\section{CASE STUDY: MONKEY TALES}

Monkey Tales is an educational math game for children in primary school. The game is available in different difficulty levels, targeted at children from different age groups. Additionally, Monkey Tales is available in a 'school version' and a 'home version'. The school version is targeted at classroom use: it complements didactic school materials, and gaming elements are more limited than in the home version. The home version, on the other hand, contains more elaborate gaming elements to stimulate children to practice math in a fun way. The game versions form a continuum, as children can play the school version in class, focusing more on math, and less on gaming. At home, they can also engage in math exercises by playing the home version, with an emphasis on the fun gaming aspects, and less emphasis on the math.

In this paper, we study how children engage with Monkey Tales in the home context. We used the home version for children in the $5^{\text {th }}$ and $6^{\text {th }}$ grades of primary school (age 10 and 11+). In class, teachers will often mediate children's use of the school version in the classroom more explicitly and consciously: the game is part of the didactic curriculum, and this can strongly influence the perception and appropriation of the game. In the home context, the mediation by parents can be expected to be less explicitly didactic. The goal of this study, then, is to investigate the use of the game at home, in an environment which is not as explicitly goaloriented as the class context [44].

\section{METHOD}

The methodological implementation of the framework presented in Section 3 consists of three stages: multimodal analysis, user research, and a meta-analysis stage [17]. Below, we will describe the three stages, and how they have been applied in studying Monkey Tales.

\subsection{Multimodal Analysis}

The multimodal analysis relates to RQ1: in this analysis, we study the design strategies in the game by focusing on the way different modes work together in a 'multimodal ensemble' [38] to communicate the central game message. To study this, we analyze the game, and how design strategies are used to guide players through the game. The analysis consisted of several steps:

1. Playing and 'reading' the game as a whole.

2. Focusing on individual game aspects and modes. We used existing game evaluation frameworks by Winn [59] and Mitgutsch and Alvarado [42] to determine the important modes to be analyzed: specifically, we focus on the (narrative) structure, the visual design of the game, and its interactivity. After a separate analysis of these modes, we bring them together, discussing how the modes contribute to a central, coherent game experience, and how they guide users in their interaction and interpretation (reconstructing the model user).

3. Checking the high-level analysis (step 1) against the low-level modal analysis (step 2), and refining iteratively. As such, we used a hermeneutic approach [26] in order to validate our analysis: we checked the analysis of individual modes 
against the interpretation we made of the game as a whole, and vice versa. Considering that the individual modes collaborate to communicate the same message, it is the coherence between low-level analysis and high-level analysis that validates the analysis.

4. Completing the analyses in 2 and 3 with additional analyses of specific aspects that emerge from the user research (section 5.2).

5. Bringing together the analyses in steps 2,3 and 4 in a global analysis of the game, and describing the overall design strategies used in the game.

As such, we analyze which design strategies have been used in the game, and how these strategies try to shape the users' behaviour - in other words: how the technology constructs its ideal model user.

\subsection{User Research (Ethnographic Methods)}

We focus on user tactics (RQ2) through an ethnographically inspired user study. The Monkey Tales field study consisted of a 6-month study with 8 respondents and their parents ( 3 girls and 5 boys, aged 10 or 11). The households were recruited via Flemish primary schools: primary selection criteria were the children's age (10-11, fifth or sixth grade of primary school); their math attitude (do the children like math in school?) and performance (are they good at math in school).

The home version of Monkey Tales was introduced in the households specifically for the study. Data collection consisted of three parts: a one-month diary study (Figure 2), interviews accompanying the diary study, and a long-term user experience study using the MemoLine method (Figure 3; [58]) in which 6 out of the initial 8 respondents participated.

- The diary focused on play sessions with the educational game, asking children to describe their playing experience (e.g., using the word cloud in Figure 2), and asking when they played and for how long, which aspects of the game were fun, whether they received help while playing, etc. Apart from these game sessions, the diary also included more general questions (e.g. hobbies, favourite subjects at school) and game specific questions (about game characters and mini games embedded in the game - see Appendix A for list of diary questions).

- Upon collecting the diaries, semi-structured interviews were held with both children and parents. While there were clearly separate interview parts for children and for parents, the parents did facilitate their children's interviews when necessary. Generally, the interviews focused on more detailed aspects of the game experience, the children's and parents' attitude towards educational games, gaming as a hobby in general, etc. (see Appendix B for the interview guide used during the interviews).

- Using the MemoLine method, the children were interviewed six months after the game was introduced, offering insight into how the children's playing behaviour evolved over a longer period of time. During the MemoLine sessions, the children filled out the MemoLine instrument (Figure 3) - a childfriendly adaptation of the UX Curve method to study long-term user 
experience ([58]; see Appendix $\mathrm{C}$ for a full description), and a final questionnaire about their overall experience with Monkey Tales. Together with MemoLine and the questionnaire, an interview was held in order to elaborate on the respondents' answers.

After the diary study and the accompanying interviews, respondents received a gift voucher of $€ 50$ (diary study) or $€ 100$ (diary study + long-term study) as an incentive.

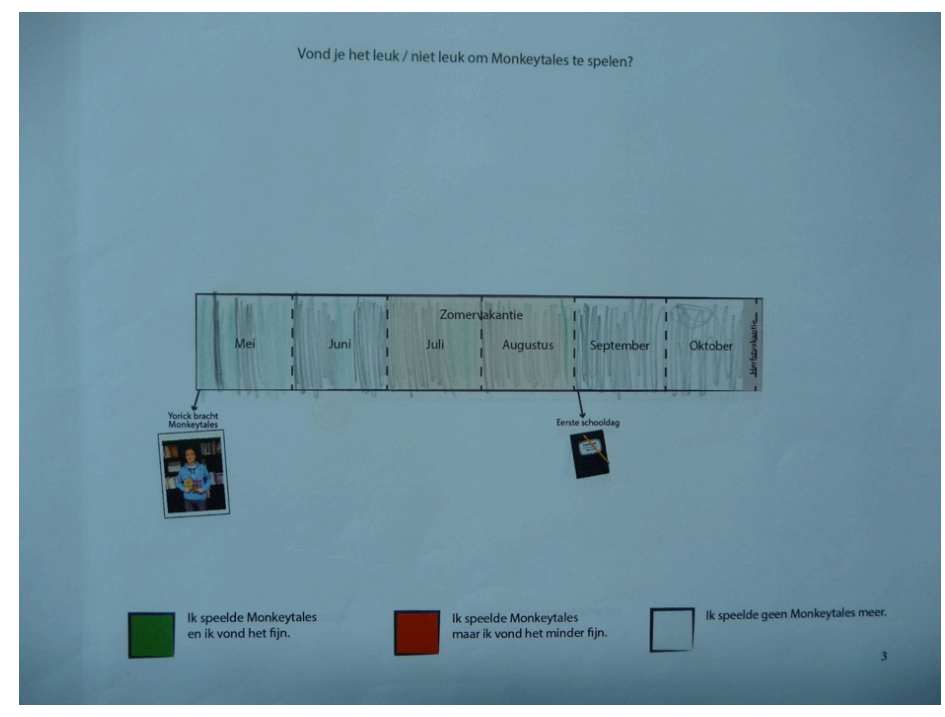

\section{Figure 2. Diary study sample.}

The diary contents, MemoLine instrument and interview transcriptions were analysed through a grounded theory methodology: the data was summarized in openended codes, which were in turn grouped together into themes. In these themes, various uses and appropriations of the game emerged, and this resulted in an overview of different user tactics. This qualitative part of the study did not seek to generalise the findings to players of educational games in general, but focused on providing rich accounts of players' individual interpretations and uses.

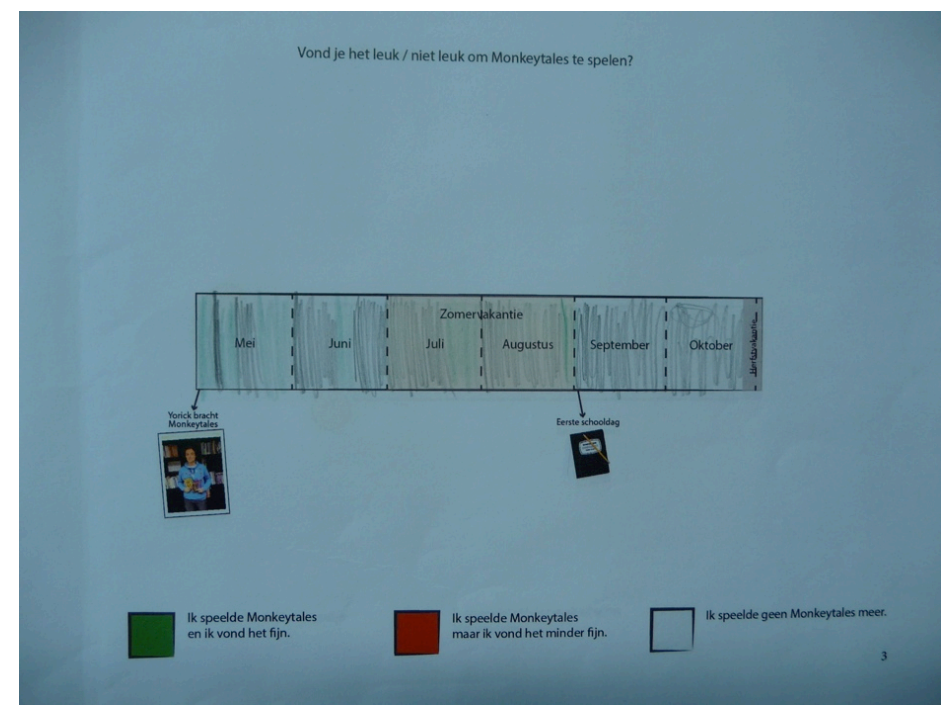

Figure 3. Timeline part of the MemoLine long-term user experience study. 


\subsection{Analysis of the Relation between Design Strategies and User Tactics}

In order to formulate an answer to RQ3, we analyzed the relation between the game's design strategies and the users' playing behaviour and tactics by relating the multimodal analysis to the user tactics emerging from the ethnographic study. When the user tactics focused on aspects that were still underexplored in the design strategies analysis, the multimodal analysis was extended iteratively to provide more detail, going back and forth between strategies and tactics.

This analysis showed to what extent the game structure effectively guides the users. Where players resisted or extended the model user implied in the game, the rich ethnographic data provided details on how both individual and contextual factors influenced the players' appropriation. In other words, it becomes possible to analyze user tactics as practices emerging from contextual factors and the technology design strategies. These contextual factors and design strategies provide a background to investigate the logic underlying individual appropriations and tactics. Such an underlying logic emerges, for instance, when patterns emerge that combine a specific type of user behaviour with specific contextual factors, across different users. In this way, user behaviour can be analyzed in order to determine whether the observed practices were idiosyncratic, or whether the appropriation tactics can be generalized to other, similar practices.

\section{RESULTS}

\subsection{Multimodal Analysis}

\subsubsection{Structural Analysis: Solving Math Problems to Move Forward}

Monkey Tales players go on a mission to defeat a central opponent, as this opponent has evil plans to steal all knowledge from the world. During their journey, players have to free monkeys from captivity, to take over their knowledge. These monkeys are then transferred to a 'monkey Zoo': apart from freeing them, players also need to collect enough bananas during the game to feed the monkeys in this Zoo. While liberating monkeys and collecting bananas, players have to avoid the opponent's traps and accomplices. When all monkeys are rescued, the game ends with a clash between the player and the central opponent.

The structural analysis showed that the game offers this story in three main game layers, visualized in Figure 4. The top layer is the story layer, in which the story of the player's adversary is told. The actual game levels are embedded in the story layer: these are rooms or enclosed areas in a 3D world the player has to pass through. Every room is a 3D puzzle: players have to find their way to the exit of the room by moving around wooden boxes and mirrors. Meanwhile, they should avoid traps and adversaries, and collect bananas. In every 3D world level, players encounter a monkey with an arcade game machine next to it. The monkey can be freed by winning an arcade mini game. This structure suggests that the educational heart of the game is located in these mini games: players leave the 3D world, and play the mini game with math exercises embedded in them. Winning this mini game frees the monkey, and opens the door to the next game level. 


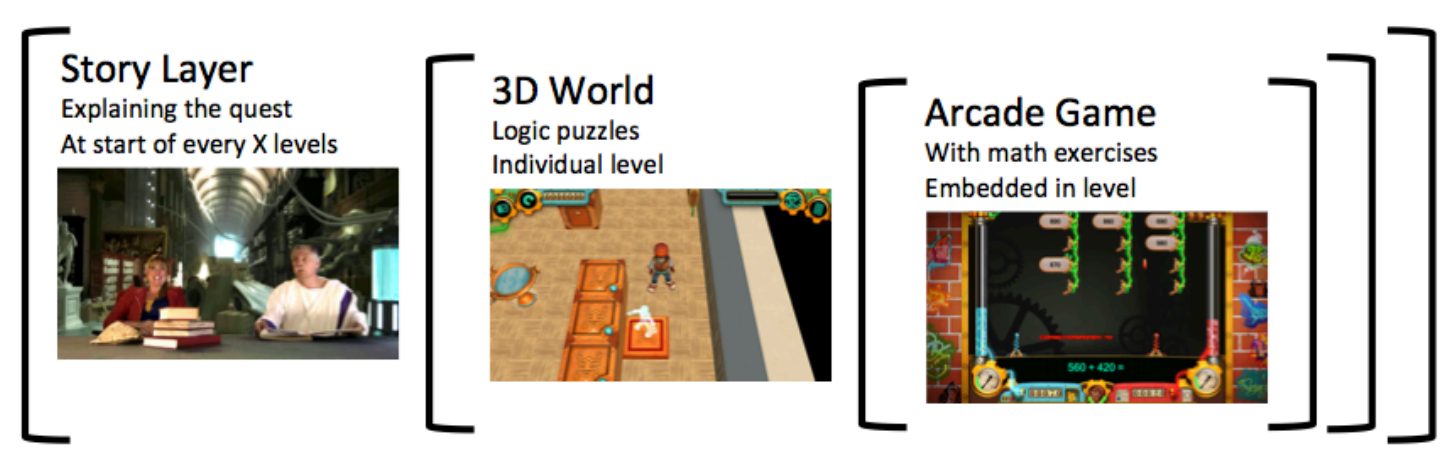

Figure 4. Main game structure.

The results of the analysis showed that Monkey Tales can be categorized as what Juul has called a 'game of progression': it is a game in which "the player has to perform a predefined set of actions in order to complete the game" [35]. This is the result of the fact that players move through the Monkey Tales world in a controlled way: they occasionally have some freedom to make choices and to explore the game world, but "the only interesting experiences [are] to be had in one direction" [35]. In this rather rigid game structure, the educational material is embedded in the third, lowest game layer: the two layers above the mini game layer are mainly game and narrative-oriented. While embedded at the deepest game layer, the educational content is crucial to make progress in the game: the game design prevents players from moving to the next game level without winning one math mini game per level, a feature related to the game's structure as a game of progression. Apart from this game structure, the game menu also offers the option to play the mini games separately. By offering this option, the game arguably augments its 'educational' factor, allowing users to take math exercises more regularly. Players are required to play a minimum of at least one educational mini game per level - if they want, they can practice more.

While Figure 4 clearly separates the different game layers, the multimodal analysis showed that boundaries are not always as clear-cut: different layers do melt into each other. In some 3D world levels, players have to cross 'the Bridge of Death'. This bridge consists of tiles, some of which are broken. To highlight the next 'safe' tile, players have to solve a math exercise correctly (Figures 5 and 6). These levels present a significant deviation from the general game structure in two ways. First, the math content moves up from the arcade game layer to the 3D world layer (see Table 1). Second, the consequences of providing the correct or wrong answer to individual math problems also become more prominent. While players are judged on the basis of their overall score in the arcade games (the arcade game 'forgives' mistakes, as long as players win the arcade game as a whole), every single answer becomes important on the Bridge of Death to learn about the next safe tile to step on. 


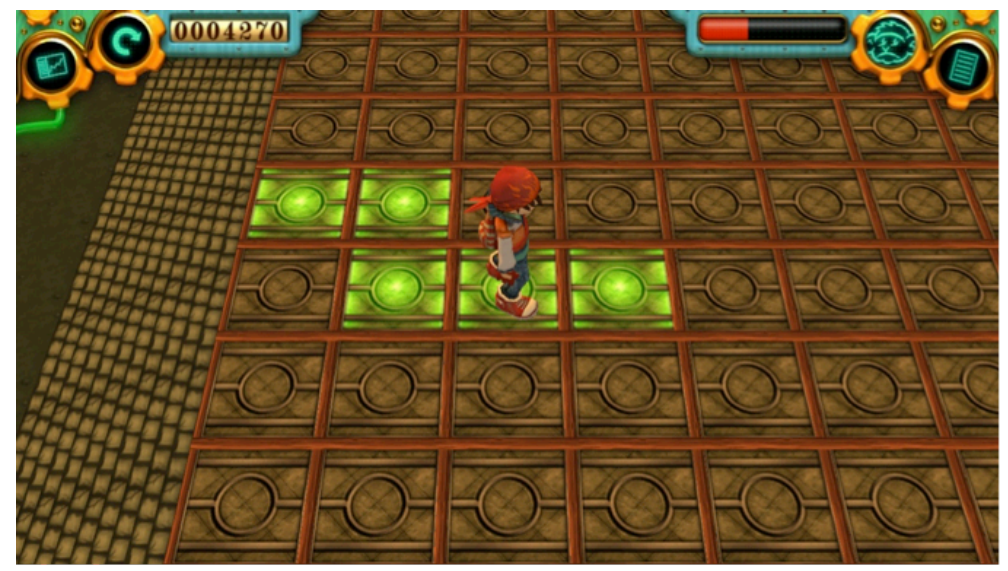

Figure 5. Bridge of Death: 3D world bridge.

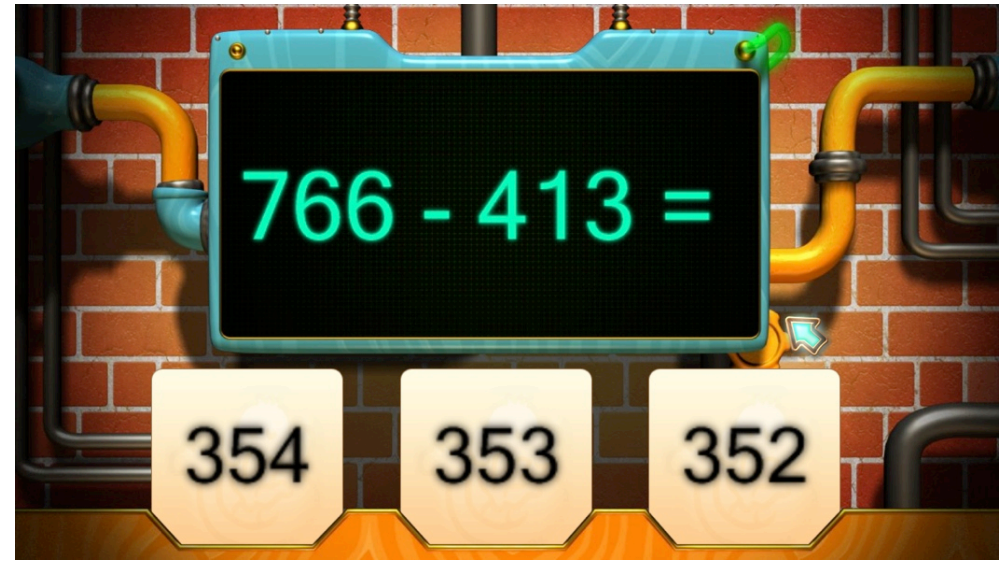

Figure 6. Bridge of Death: math exercises.

\subsubsection{Visual and Narrative Analysis: Reinforcing the Game Structure}

The structural analysis into three separate game layers is reinforced through other modes, e.g. the game's visual style: the game uses three distinctly different visual styles. The consistent use of these styles strengthens the internal coherence of the game, clarifying the game structure. The visual styles also reinforce the two distinct chronotopes in the game, in the Bakhtinian sense ('time-spaces'; see also [3][40]): there are different tempos of action, and different movements from place to place throughout the game. The story layer and the 3D world layer construct the same chronotope (the game narrative, with the player moving towards the central opponent). The arcade game environment, however, is different: it presents very different game universes, such as space environments.

The distinct visual styles serve as an additional visual cue where the game layers merge into each other. Where one layer 'intrudes' in another game layer, every message is consistent with the visual style of the original layer. For instance, in the Bridge of Death levels, the exercises belong to a different game layer. The Bridge itself is located in the 3D world (Figure 5), but the exercises on the Bridge are offered in the visual style of the arcade games (Figure 6). 


\subsubsection{Interactivity and Pace: Merging Math Skills and Gaming Skills}

The three game layers offer three kinds of interactivity - this interactivity profoundly influences the game's pace. The story layer, with the cut-scenes of actors explaining the game's goals, contains no interactivity. The 3D world offers an interactive first-person logic puzzle. While there are adversaries to be avoided in these levels, there is no active fighting. This makes the 3D puzzle a game of reflection and strategy, rather than an action game. Players can play these levels at their own pace, taking their time to figure out the 3D puzzles with little time pressure.

The arcade games offer an entirely different game genre. Contrary to the 3D world, the arcade games do include time pressure: players have to shoot or collect the right items as fast as possible. The arcade games are played in competition with the captivated monkey: if players are too slow or give too many wrong answers, they lose the game. This added time pressure is significant as a design strategy, as it has the additional effect that players need to divide their attention between solving the math, and the actual game mechanics (shooting, avoiding traps, etc.). The time pressure makes sure players have to solve the math exercises fast, but it also de-emphasizes the math exercises, as players have to divide their attention across different tasks. The math-solving skill becomes only one of the various skills needed to play. The time pressure, however, is not present in the Bridge of Death levels: as a part of the 3D world, players can solve the Bridge of Death exercises at their own pace. In this sense, the Bridge of Death not only stands out in the structural analysis: when looking at the interactivity, there is also a significant difference in time pressure between arcade game exercises and Bridge of Death exercises.

\subsubsection{Design Strategies: The Ambiguous Role of Math}

The multimodal analysis above allows us to answer RQ1: it shows that the game uses specific design strategies to guide players through the game: narrative, visual and interactive modes reinforce each other in communicating the overall game structure (see Table 1). Table 1 visualizes the multimodal cohesion ([57]; [42] refers to 'coherence' and 'cohesiveness') within and between different layers. The story layer and the 3D world form a unity (i.e., the light gray areas in Table 1, indicating the main game narrative). The educational part of the game is merged with game elements, but it is located in a game layer that is recognizably separate visually, interactively, and in the game narrative (i.e., the dark gray areas in Table one). The arcade games involve math exercises, but are packaged in mini games that include time pressure and other skills. The Bridge of Death levels present a deviation from this overall structure: the Bridge of Death is located on the 3D world layer, but there are math exercises, which are not combined with other skills, or with time pressure. In other words, the Bridge of Death combines structural features from both chronotopes (both ligth and dark gray aspects in Table 1). 


\begin{tabular}{|c|c|c|c|c|}
\hline Game layer & Story layer & 3D world & $\begin{array}{l}\text { Bridge of } \\
\text { Death }\end{array}$ & Arcade game \\
\hline Visual & $\begin{array}{l}\text { Realistic } \\
\end{array}$ & $\begin{array}{l}\text { Third-person } \\
\text { game world }\end{array}$ & $\begin{array}{l}\text { Third-person } \\
\text { game world } \\
\text { math exercises } \\
766-413= \\
354 \quad 353 \quad 352\end{array}$ & 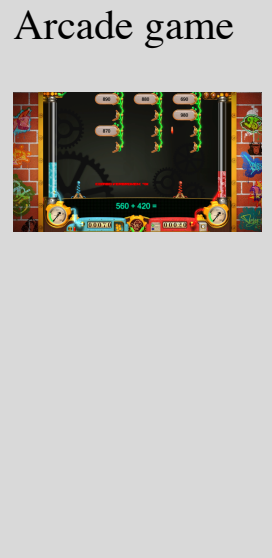 \\
\hline Interactivity & No interaction & $\begin{array}{l}\text { Third-person } \\
\text { interactivity, } \\
\text { logic puzzle, no } \\
\text { time pressure }\end{array}$ & $\begin{array}{l}\text { Third-person } \\
\text { interactivity, } \\
\text { math exercises, } \\
\text { no time pressure }\end{array}$ & $\begin{array}{l}\text { First-person } \\
\text { interactivity, } \\
\text { math exercises, } \\
\text { time pressure }\end{array}$ \\
\hline Narrative & $\begin{array}{l}\text { Main } \\
\text { narrative: } \\
\text { explanation of } \\
\text { quest }\end{array}$ & $\begin{array}{l}\text { Main narrative: } \\
\text { executing quest }\end{array}$ & $\begin{array}{l}\text { Main narrative: } \\
\text { executing quest }\end{array}$ & $\begin{array}{l}\text { Inside arcade } \\
\text { game }\end{array}$ \\
\hline
\end{tabular}

Table 1: Analysis of the Monkey Tales story layers.

Following this structure, model users encounter an elaborate game narrative in the story layer and the 3D world layer. The math component is embedded at the lowest level of the game. On the one hand, the 'progression' structure in the game [35] forces players to play and win the math aspects in the game. On the other hand, the mathsolving skills are backgrounded both structurally (embedded at the lowest game layer) and interactively (merging math-solving skills with various other skills). The math in Monkey Tales, therefore, has an ambiguous status: while the game severely limits personal choice, and forces the player to score well in the mini games, other aspects of the game background the importance of the math.

In the next sections, we will explore how players play, and appropriate the game (Section 6.2), and how players' appropriations relate to this ambiguous status of math exercises in the game (Section 6.3).

\subsection{User Study}

Players' interpretations of the game are not only guided by the game itself: specific, contextual habits and the discourse used to talk about educational games also play a role in the use and interpretation of the game. Playing behaviour and discourse can provide a 'way in' to understand how people generally think about the technology 
[29]. We first investigate parents' and children's discourse surrounding the educational game to find out how they see it. Afterwards, we discuss playing experiences and tactics.

\subsubsection{Parents and Children: Negotiating the Education in an Educational Game}

All educational games played at home need to be introduced at some point, either via teachers or via parents. Together with this introduction, the nature of the game and the rules surrounding it need to be clarified. At home, games can be familiar and enjoyable 'affinity spaces' for children [44], while in school, interest in and engagement with educational content are known sites of struggle. As educational games like Monkey Tales combine fun and education, the 'accepted' view on educational games is open for discussion: 'merely a game', or a useful educational tool[18]. For instance, the mother of respondent 3 commented on her attitude towards (non-educational) video games:

Mother of respondent 3, interview: I don't think we see [gaming in general] as a hobby, we're struggling a bit against that... (laughs) So it surely is there, we own a Wii, and... But the children can't play with it unlimitedly.

Most parents did not like their children playing computer games too much: in the study, parents reported that they kept an eye on their children's computer use, and limited that time if necessary: six out of eight parents or children confirmed this in their diaries or interviews. However, the parents in the study expressed a rather positive attitude towards educational games: parents explained that if they cannot stop their children from playing video games anyway, educational games at least have the benefit that they can potentially teach their children some useful skills. Three parents specifically mentioned educational games as a way of practicing skills their children are struggling with at school. Consequently, all parents expressed an interest in educational games: all parents reported having watched their children play the game at least once (two parents even played themselves, to get to know the game their children were playing), and felt more at ease because of the perceived benefit of the game's educational aspect. However, this parental supervision was present only for a short period after the introduction of the game. After an initial period of getting to know the game, parents only intervened to limit their children's play time.

Mother of respondent 2, interview: Yes, I think they [educational games] are useful, because he likes playing computer games, and in that way, they could learn something. They do have to be playful, so I think this... [the game] was a good combination.

The children in the study were very much aware that their parents had a more positive attitude towards educational games than towards 'regular' video games. Several parents allowed their children some more freedom: interview data showed that respondents 2, 3 and 4 were allowed to play the educational game longer than 'regular' games. The parents' more positive attitude was used in negotiations about when and how long the respondents were allowed to play. Even during interviews with both parents and children, some children continued to convince their parents that the game is a 'good' game worth playing. To this end, they emphasized the educational content, stressing how difficult the exercises were. 
Mother of respondent 8, interview: Actually, he only counted the thousands, or something like that. The consequence is that you can start estimating - those numbers [to choose the right answer from], they were really like 6000 or 5000, or,... So you can immediately see...

R8: But no!

Mother: So I think if the numbers would have been closer together... R8: But no, mom, sometimes you had to choose between 4,23; 4,24 and 4,25. (indignant) Hey, that's really difficult!

Although respondents stressed the educational aspect of the game when talking to their parents, the interviews with the children showed that they focused mainly on the gaming aspects. For instance, the same respondent 8 quoted above reported liking the game "because it's a game [...], and it's not math exercises the entire time". This view on the game came out as well in discussing it in relation to other (educational) games: the respondents compared the game more often to regular games, rather than to educational games. It was considered more 'a real game' (respondent 7), as it was more fun than most educational games they knew (respondents 2, 5, 7). Finally, the focus on the gaming elements also was apparent in the respondents' reactions to the question of how the game could be improved further. All respondents reacted to this question with suggestions regarding the fun elements in the game: they made implicit analogies to other games they play at home, suggesting game elements from other children's games, first-person shooters (respondent 6 , who also played the first-person shooter game Assassin's Creed), etc. Although all respondents reported having prior experience with educational games in the introductory interviews, either at school (5 respondents) or at home (6 respondents), no-one in the study suggested improvements regarding the way the math exercises were offered: this is an additional indication that the respondents focused on the fun, rather than on the educational mini games, despite the way they present the game to their parents.

This ambiguous attitude shows that some children use the educational content to justify playing, and to stretch the social rules surrounding computer games (getting to play longer, more often, etc.). Children foregrounded different aspects of the game, depending on the context and on whom they were addressing. In this way, the balance between the fun and the serious in the game becomes a negotiation space between parents and children in which the interpretation of Monkey Tales is at stake: primarily play or education.

\subsubsection{Playing Experiences and Tactics}

While respondents 2, 3, and 4 stretched the household gaming rules based on the game's educational factor, the interview data showed that five out of eight respondents stretched the in-game rules as well. Gaming at home is typically less monitored than in class [44]: none of the parents consistently observed their children while playing. This opened up opportunities for children to focus on their own interests, negotiating their way around Monkey Tales, and appropriating it in ways that suited them.

Before analyzing game appropriations in more detail, it is important to know whether or not the respondents liked math or gaming, as this can influence their perception of the game. Three out of eight respondents reported in the diaries that they liked math. However, with the exception of respondent 2, for these players, the 
most fun part of the game was not located in the mini games. Only respondent 2 replayed the mini games separately from the main game narrative because they were the most fun part of the game. All other respondents expressed no preference (two respondents), or thought the 3D world was more fun (five respondents), instead of the educational mini games. Concerning the respondents' experience with (educational) games, only one respondent did not play on a regular basis (less than one time per week); the other seven respondents played (non-educational) video games on PC or game consoles at least a few times per week.

Five out of eight respondents reported tactics to reach the game's goals as quickly as possible, to focus on the content they preferred, or to minimize the math effort needed to play the game. Three general strategies were reported, ranging from small adjustments in playing strategy to overturning the game's goals:

1. Finding ways to avoid unwanted content. Several respondents reported ways of skipping unwanted content. Respondents 2,5 and 8 reported ways to skip parts of the narrative story layer, which they considered unnecessary and frustrating. Respondents 2, 6 and 7 also reported frustration about having to replay mini games. The game allows players to choose whether to start collecting bananas in the 3D world, or start by playing the arcade game. However, when players first play the arcade game and then get killed in the 3D world, they have to replay the entire level, including the arcade game: To avoid unnecessary math games, respondent 2 altered his playing strategy. Even though this respondent was the only one to replay arcade games outside the game narrative, he did try to find the optimal, most efficient way to reach the game's goals.

R2: It seemed better to find the bananas first, because in the end, I sometimes had won the monkey game for nothing.

R6: I thought it was a pity [having to restart the level from scratch]. It was too bad I had to replay the same mini game against the monkey. That was annoying .

2. Guessing and estimating. The parents of respondents 5 and 8 reported extensive guessing and estimating behaviour. As some of the mini games involved multiple choice questions, respondents tended to choose the most probable answer, without actually calculating the exercise result. This sparked a discussion with the parents of respondents 5 and 8 about the educational goals: whether the goal is to really calculate the outcome of the exercises, or to become better at estimating, which can be a valuable skill in itself.

3. Focusing on game play. In the interview, respondent 8 reported strategies to focus on the gameplay rather than the math exercises in the mini games: rather than shooting the right answers to math problems (see arcade game in Figure 4), this respondent ended up shooting any answer randomly, assuming that the right answers shot 'by accident' would be enough to pass the mini-game. Cheng et al. [10] describe this type of tactic on a more general level: 'students might focus too much and locate all of their mental resources on the gameplay itself and, in the process, ignore the educational 
targets that the educational game intends to cover'.

R8: With the cannon, I always win: I just keep the space bar pressed, and I move from right to left, and it's over.

All respondents that reported tactics to help them focus on the content they preferred, played video games of any kind at least a few times per week. This suggests that prior experience in video games is related to developing specific game tactics, from small adjustments in playing strategy to actually 'gaming the system', finding 'rule loophole[s] and min-max their way through' [20]. The strongest use tactics were found with respondents with a negative attitude towards math, with especially respondents 5 and 8 combining several tactics.

In analyzing how the respondents coped with the educational content, The Bridge of Death levels (Figures 5 and 6) presents an interesting case. These levels combine characteristics of different layers: educational content is offered without time pressure or the need for gaming skills, making the math much more prominent. Five players spontaneously mentioned the Bridge levels: three reported especially liking them (R3, R4, R7), as they offered a combination of solving math exercises and an element of chance if an exercise was answered incorrectly (see quote by respondent 4 below). Two respondents (R6 and R8) particularly disliked these levels, as it involved making too many exercises (see quote by respondent 8 below). Interestingly, though, these respondents did not dislike any of the mini games in particular, some of which involved shooting the answers to the same number of exercises as in the Bridge of Death. This suggests that for these players, the added time pressure and game mechanics make an important difference in their perception of the number of exercises they have to make. This makes the Bridge of Death an atypical part of the game, both structurally (see Table 1), and in the players' perceptions.

R4: I thought it was fun that... you had to solve the exercises correctly, and if you didn't solve them correctly, you had to guess, really, where [to which tile] to go next.

Diary R8: The Bridge had too many exercises for me.

\subsubsection{Monkey Tales over Time}

The follow-up interviews after six months revealed that only two respondents (out of the six that agreed to have a follow-up interview) continued playing the game for more than three months after introducing the game. The respondents mentioned two main reasons: on the one hand, the game was introduced in May. This meant that two months later, the summer holidays started, during which most children had other activities to engage in. On the other hand, most players stopped playing after they had finished the final level of the game: this is a consequence of the 'game of progression' structure (see section 5.1). The game allows players to play the mini games separately, but not the 3D world levels (see Figure 4) in which the math games are embedded. The only way of replaying the $3 \mathrm{D}$ world levels is by creating a new avatar, and restarting the game narrative.

For only two respondents, the game 'lasted longer' than the game narrative: respondent 2 played individual mini games, and respondent 4 created a new avatar, and restarted the entire game narrative. The other respondents stopped playing the 
game after finishing the last game level, with respondents 2,5 and 7 reporting in the follow-up interview they would have liked to replay individual 3D world levels. The respondents' parents also commented on this: if they would buy an educational game for their children, they expect it to last longer than a few play sessions. In this sense, the game structure in which only mini games can be played individually has implications for the lifespan of the game.

R7: But I can't replay those levels. I don't like the fact that you can't do that. [...] I would just like to go back to a level that I want to play again.

\subsubsection{User Study: Discussion}

Based on the results presented above, we can answer RQ2, and clarify how user tactics are used to appropriate Monkey Tales. The aim of the user study was not to create a fixed, exhaustive typology of user behaviour. People's behaviour is inherently messy, and based on a long-term study with 8 respondents, it is not feasible to create such a typology. However, the rich accounts of players' individual interpretations and uses do show a clear variation in appropriation. On one end of the spectrum, respondent 2 is a player that likes math in school. The mini games are his favourite part of the game, and he played the mini games independently from the main game. Overall, this respondent was most open to the educational aspects of the game. At the other end of the spectrum, there is respondent 8 , who showed the most extensive math-avoiding behavior, and disliked the Bridge of Death levels. This respondent reported disliking math in school, and did not play individual mini games. The other respondents can be situated in between the 'extremes' of respondents 2 and 8 .

Based on this variation in behaviour, the individual respondents in the user study have different profiles, and 'tolerance levels' for math content in Monkey Tales. Respondents that like, or are good at math in school generally have a higher tolerance level: consequently, they play the educational aspects of the game as well as the more fun aspects of the game, while respondents that dislike math in school generally have a lower tolerance level, and primarily like to play the fun parts of the game. Consequently, the latter players develop math-avoiding strategies. It is important to note, however, that these tolerance levels are not fixed, but rather an abstraction of their specific behaviour. Depending on the respondents' momentary goals and wants, they can change their behaviour, either gradually, or even abruptly between play sessions [60].

\subsection{Analysis of Design Strategies and User Tactics}

Based on the multimodal analysis and the ethnographic user research, we can now turn to RQ3, to specify how user tactics are related to specific design strategies. Our study shows that the characteristics and affordances in the game shape the gameplay in important ways: the affordances indicate how players can or should interpret and play the game. The analysis presented in Section 6.1 showed how the game guides its players, and how it expects its players to behave. When comparing this analysis of the game to the user tactics emerging from the user study, it becomes clear that the various user tactics are more diverse than the design strategies suggest. In other words, the players' individual interest and engagement lead to tactics and 
appropriations that go beyond the model user implied by the game. We distinguish between two general types of user tactics.

The first type of user tactic is social in nature. It is related to the overall game structure, but is used in social interaction surrounding the game, rather than in game play itself. Players use the dual nature of educational games, and the flexible gaming rules at home to foreground either the fun aspects or the educational aspects, depending on their specific interest in a social situation. While the second type of user tactics is more directly related to the game's structure, it is also related to the informality of the home context. We distinguish a continuum, with three playing tactics: complying with the design strategies in the game, resisting the design strategies, and finally, rejecting them (see Table 2).

\begin{tabular}{|c|c|}
\hline Design Strategy & User Tactic \\
\hline $\begin{array}{l}\text { General structure: } \\
\text { Mix of gaming and math; math } \\
\text { content embedded at lowest level } \\
\end{array}$ & $\begin{array}{l}\text { Stretching the social gaming rules: foregrounding } \\
\text { game elements or educational content depending } \\
\text { on the specific interest in a given situation. }\end{array}$ \\
\hline $\begin{array}{l}\text { Narrative content embedded in a } \\
\text { separate game layer } \\
\text { Freedom to choose when to play } \\
\text { the arcade game in 3D world } \\
\text { levels }\end{array}$ & $\begin{array}{l}\text { Comply with specific design strategy: } \\
\text { skipping narrative story layer } \\
\text { finding the optimal playing order }\end{array}$ \\
\hline $\begin{array}{l}\text { Math content embedded in arcade } \\
\text { games with time pressure, in } \\
\text { combination with other skills }\end{array}$ & $\begin{array}{l}\text { Resist specific design strategy: } \\
\text { foregrounding gaming skills at the cost of math } \\
\text { skills }\end{array}$ \\
\hline $\begin{array}{l}\text { Allowing players to replay only } \\
\text { math games }\end{array}$ & $\begin{array}{l}\text { Reject specific design strategy: } \\
\text { not using the replay features embedded in the } \\
\text { game; stop playing }\end{array}$ \\
\hline
\end{tabular}

\section{Table 2: Overview of user tactics.}

First, some users comply with the design strategies, but do make optimal use of the game's internal structure to meet their needs. The players that skipped the narrative story layer, or altered their playing strategy during the game to avoid playing unnecessary mini games made optimal use of the game structure. The game allows for these strategies through its specific structure, and by not imposing a specific playing order. Hence, players make their choices within the boundaries of the game's flexibility, and optimize their playing by the choosing one of the strategies the game allows for.

Second, users resist the game's model user. The extensive guessing and estimating behaviour, and the tactics of 'hacking' the mini games show that users do find strategies to get around the design strategies in creative ways. Players resist the game design by trying to avoid the game aspects they dislike. The game structure offers very little flexibility in the mini game layer (players have to win one game per 
level in order to progress). As this was a rigid requirement, players bended the rules to suit their needs.

Third, users reject some of the game's design strategies. The game structure allows replaying individual mini games, but does not allow for replaying individual 3D world levels. However, respondents reported they actually wanted to replay the $3 \mathrm{D}$ world levels, and were not interested in replaying mini games. In this way, what the players want is at odds with what the game offers. The players stopped playing, rejecting the game structure entirely. The design strategies aimed at promoting the educational content met user resistance and actually reduced the potential lifespan of the game. This type of user rejection can be seen as a case of 'non-use' of technology (e.g. [4][48]) due to the mismatch between what the game offers and what users want: it is a specific type of technology non-use that can be interpreted as an extreme position in the continuum ranging from user compliance, over user resistance, to user rejection.

Using these tactics, users creatively cope with the game's design strategies: what the players actually do with the game is not fully determined by the design, but also by the interests of the child (interest in math), the relationship between players and their parents, the rigid gaming rules at home, etc. In the Monkey Tales study, the loose rules surrounding the game created opportunities to reinterpret the game in personal and creative ways. While these factors are very personal and situation-dependent, it is important to acknowledge that they are important in actual use. In the end, players appropriate the game, and can develop social tactics and tactics related to game structure to reinterpret and bend the game's design strategies.

\section{DISCUSSION}

\subsection{Implications for the Design and Evaluation of Educational Games}

The major finding of this study is that in the home context, the balance between game aspects and educational content is not a fixed game characteristic but an emergent one. On the one hand, the nature of the game content - useful education, merely a game, or a combination of both - and the rules surrounding the game are subject to constant renegotiation between parents and children (see also [18]). On the other hand, in this flexible context, children have the opportunity to use various tactics to focus on the game content they are interested in, often reducing the amount of educational content they deal with. Although we have investigated this emergent balance between game aspect and educational content specifically for one specific case study, the study findings touch upon issues that are relevant for other educational games as well. To what extent do design strategies in educational games determine the balance between play and education? How does a specific context, such as the home context, relate to these design strategies, and how does it alter the balance between game aspects and educational content?

The role of the context in the emergent balance between game aspects and learning (e.g., in the social tactics developed by the players) implies that one should be cautious in extending the findings of effectivity studies to the home context, as they often use interventions in formal class settings. Although more research on the integration of digital games in classroom settings is needed [56], existing research 
points to the fact that well-considered classroom management, including the design of the curriculum and mentorship surrounding the game, is a very important aspect when integrating games in the curriculum [49][52]. Therefore, we can expect that in a class situation, games will be more explicitly part of a didactic curriculum: playing games will be mediated more strongly by the teacher. At home, however, players often have more freedom: the rules on when, how, or how long to play are less strict [53]. Researchers should therefore acknowledge that understanding both players' personal motivations and the context in which the games are played are crucial: learning and gaming emerge in the space where design strategies, player intentions, tactics, and context meet [46][51]. For instance, our study suggested that children with a strong dislike for a specific educational subject matter - and therefore a low 'tolerance level' for that type of content in games - can be expected to develop more elaborate avoidance tactics than children that like, or are better at, that subject.

The emergent balance between gaming and educational content described above has implications not only for the evaluation, but also for the design of educational games. Since players can and do develop avoidance tactics, the question rises whether educational game designs can or should try to prevent this behaviour through their design. Should educational games specify more rigid rules to enforce educational content? We do not think so. Arguably, play inherently implies negotiating your own way around a game, trying out different things and seeing what happens, and even bending and breaking the rules [41]. Stueber [54] states that no rule can ever fully specify how to be enacted - consequently, imposing even more rules to prevent gaming the system merely generates even more opportunities for gaming the system [20]. Therefore, we would argue for a different approach. Our results on the appropriation process of educational games point to opportunities for game designers to design more flexible games that leave more room for appropriation and interpretation [50]. In more flexible games, designers can consciously allow players some choice to focus on either gaming aspects or on educational content. The challenge in designing educational games, then, shifts from enforcing the ideal player behaviour, to designing educational games in a way that players do not feel the need to develop elaborate resisting and avoiding tactics. In this view, a more adaptable, personal and context-dependent boundary between play and education might be a fruitful way to design educational games. Designers should be aware of the fact that at least a subset of players will not show the 'model user' behaviour implied by the game's design strategies, but will develop unpredictable tactics to reach or avoid specific game content. Moreover, design strategies that directly conflict with the users' needs can even lead to users rejecting the model user entirely, and cause the players to stop playing the game. An adaptable, more 'open' game design will allow players more freedom in choosing which content they want to engage with; players will continue to play in unpredictable ways, but a more open initial game design can cater for a wider diversity of educational content tolerance levels.

This more 'open' game design, then, raises questions about the relation between educational content and game content in educational games. Designers of educational games generally agree that instead of merely 'sugarcoating' the unpleasant educational content with game elements, a tighter integration between learning content and game elements is desirable (e.g., [5][33]). In the case study, however, the design strategy separating game content and educational content in separate game layers was seized by players as an opportunity to direct their focus clearly towards the 
gaming layers, finding ways to avoid the compulsary education content. In order to design an adaptable and personalized boundary between play and education into an educational game, the case study results suggest that the educational part of a game should be at once tightly integrated with the game elements, but should also not be made too rigidly compulsory. We do not suggest that educational games should have a completely open-ended design that allows players to choose freely between gaming and educational content whenever they like. Games need to guide their users, but instead of rigidly imposing educational tasks, game designs can be considered in which the educational parts are not rigidly compulsory. Allowing players some choice in the educational parts as well can help in preventing the avoidance behaviour. For instance, offering players a choice between a minimum of tightly integrated learning content, and engaging in additional, more elaborate educational content (for instance, to gain extra points in the game) might be a fruitful way of allowing players some freedom of choice within educational games. This additional learning content, then, can be integrated in the game in an optional side track of the game, allowing players to skip or postpone this content. While this additional educational content should still be integrated tightly, it can be left to the players to decide whether to score extra bonuses by engaging in the additional content. This is but one example of how an educational game could cope with their players' various interests, and their different tolerance for educational content.

\subsection{Design Strategies and User Tactics as an Analytical Lens}

This study on educational games started from the assumption that user interpretation is not a matter of mere passive reception. Through their use, users actively impose new meanings on the artifacts they use, and appropriate them. While appropriation has been researched in HCI from several perspectives, including sociological [19][23] and cognitive [47] ones, our study adds an interpretative perspective: it investigates users' interpretation-in-context. The method used in this paper allows for a detailed analysis of how users form interpretations based on the application on the one hand, and the context on the other. As such, the study exposes the consequences of design choices in specific contexts of use.

While interpretative approaches are still rather uncommon in HCI, researchers have emphasized the value of interpretative methods "as a valid form of knowledge production inside HCI" [37]. In our study, the interpretative semiotic analysis, validated in a hermeneutic approach, is a crucial component, as it shows how the technology shapes the user's interpretation by promoting and discouraging specific behaviour [38]. The combination of the semiotic approach with the ethnographic research methods reveals to what extent an application actually succeeds in changing user behaviour in daily life, and to what extent personal or contextual factors play a role. Specifically, it offers novel insights into how and why users resist or reject the application's model use, and develop alternative strategies to suit their specific needs.

\section{CONCLUSION}

Our analysis of Monkey Tales' appropriation by children has led to more nuanced understanding of how players cope with the design strategies embedded in an educational game. Based on this specific case study, we tackled the wider question of 
the relation between educational games and the home context, showing how and why children develop tactics that oppose or subvert this model user behaviour.

We acknowledge that in this article, we focused on one particular case study, and involved only a relatively small number of respondents: this means we cannot provide a generalizable picture of the appropriation processes of educational games at home. While the interpretive method used in this research is useful for researching the relation between user behaviour and technology of a limited group, it is not suitable for use with large user groups. The method is especially applicable in in-depth, smallscale user trials of a specific application, such as the user study conducted with the educational game reported in this article. As such, the method relies on its 'ecological' validity (see, e.g., [11] for a discussion of validity in HCI, and [15] for a discussion of ethnographic validity) by providing detailed, longitudinal data of the respondent group. In line with the aim of the study, we have shed light on how players' interpretations and playing styles differ, suggesting that a better, richer understanding of the appropriation processes of educational games has important implications for both the evaluation and design of educational games.

The study showed that the players' tolerance for educational content plays an important role in the extent to which children develop tactics that are either based on the social context in which the game is played, or on the specific constraints imposed by the game. These results stress the importance of taking into account contextualized playing practices in the evaluation of educational games. Beyond the home context, these insights suggest that an in-depth understanding of the contextualized nature of educational gaming in classroom settings also merits further attention. Games targeted at classroom settings can be expected to have a more school-oriented design, with a different balance between gaming and educational content. Additionally, other contextual factors such as classroom dynamics, the teacher-pupil relationship, and the place of gaming in the school curriculum play a part in the appropriation of games at school. How these contextual factors in the classroom influence the players' specific tactics in determining the emergent balance between gaming and educational content is an interesting topic for future research.

\section{ACKNOWLEDGEMENTS}

This research is part of $\mathrm{G} @ \mathrm{~S}$, a project cofunded by iMinds (Interdisciplinary institute for Technology), a research institute founded by the Flemish Government. Companies and organizations in the project are Meaningful Interactions Lab, CiTiP and ITEC (KU Leuven), SMIT (VUB), MICT and Data Science Lab (UGent), Belgacom, Larian Studios, Grin Multimedia, Die Keure, with project support of IWT. 


\section{REFERENCES}

[1] Aarseth, E. I Fought the Law: Transgressive Play and the Implied Player. Proceedings of DiGRA 2007 Conference. Tokyo, JP: The University of Tokyo, Tokyo, 2007, pp. 130-133.

[2] Ahmad, W.F.B.W., and Latih, N.H.B.A. Development of a mathematics courseware: fractions. In: Proc. ATCM 2010. Mathematics and Technology, Blacksburg, USA, 2010.

[3] Bakhtin, M. Forms of time and of the chronotope in the novel. In The Dialogic Imagination. Univ. Texas Press, Austin, TX, 1981, 84-258.

[4] Baumer, E.P.S., Ames, M.G., Brubaker, J.R., Burrell, J., Dourish, P. (2013) Refuling, Limiting, Departing: Why We Should Study Technology Non-use. Proc. CHI '13. ACM Press, New York, NY, 2013, pp. 3257-3266.

[5] Bellotti, F., Berta, R., De Gloria, A. Designing Effective Serious Games: Opportunities and Challenges for Research. International Journal of Emerging Technologies in Learning. 5 (2010, SI3), 22-35.

[6] Blomberg, J., \& Burrell, M. An Ethnographic Approach to Design. In: Jacko, J.A. The Human-Computer Interaction Handbook. Fundamentals, Evolving Technologies, and Emerging Applications. Third Edition. (pp.). CRC Press, Boca Raton, FL, 2012, pp. 1025-1052.

[7] Bourgonjon, J., De Grove, F., De Smet, C., Van Looy, J., Soetaert, R., \& Valcke, M. Acceptance of game-based learning by secondary school teachers. Computers \& Education 67 (2013) 21-35.

[8] Castellar, E. N., All, A., de Marez, L., Van Looy, J. Cognitive abilities, digital games and arithmetic performance enhancement: A study comparing the effects of a math game and paper exercises. Computers \& Education 85 (2015) 123-133.

[9] Chang, M., Evans, M.A., Kim, S., Norton, A., Deater-Deckard, K., Samur, Y. (2015) The effects of an educational video game on mathematical engagement. Educ. Inf. Technol. Available online, DOI 10.1007/s10639-015-9382-8

[10] Cheng, M.-T., Su, T., Huang, W.-Y., Chen, J.-H. An Educational Game for Learning Human Immunology: What do Students Learn and How Do They Perceive? British Journal of Educational Technology 45:5 (2014) 820-833.

[11] Chi, E. A position paper on 'living laboratories': Rethinking ecological designs and experimentation in human-computer interaction. HumanComputer Interaction. New Trends. 5610 (2009) 597-605.

[12] Chorianopoulos, K., Giannakos, M.N. Design Principles for Serious Video Games in Mathematics Education: From Theory to Practice. International Journal of Serious Games. 1:3 (2014) 51-59. 
[13] Chorianopoulos, K., Giannakos, M.N., Chrisochoides, N. Design Principles for Serious Games in Mathematics. In: Proc. PCI 2014. ACM Press, New York, NY, 2014, Article 55, 5 pages.

[14] Clark, D.B., Tanner-Smith, E.E., Killingsworth, S.S. Digital Games, Design, and Learning: A Systematic Review and Meta-Analysis. Review of Educational Research 86:1 (2016) 79-122.

[15] Davies, C.A. Reflexive Ethnography: A Guide to Researching Selves and Others. Routledge, London, UK, 1999.

[16] De Certeau, M. The Practice of Everyday Life. University of California Press, London, UK, 1984.

[17] Derboven, J. Geerts, D., De Grooff, D. Researching User Interpretation Beyond Designer Intentions. In: Proc. CHI 2013 EA. ACM Press, New York, NY, 2013, pp. 367-372.

[18] Derboven, J., Zaman, B., Vissers, J., Geerts, D., De Grooff, D. The Fun and the Serious in an Educational Game: the Monkey Tales Case. In: Proc. CHI 2015. ACM Press, New York, NY, 2015, pp. 2829-2832.

[19] DeSanctis, G. \& Poole, M.S. Capturing the Complexity in Advanced Technology Use: Adaptive Structuration Theory. Organization Science 5:2 (1994) 121-147.

[20] Deterding, S. Eudaimonic Design, or: Six Invitations to Rethink Gamification. In: Fuchs, M, Fizek, S., Ruffino, P., Schrape, N. (Eds.) Rethinking Gamification. Meson Press, Lüneburg, DE, 2014, pp. 305-331.

[21] Dicks, B., Flewitt, R., Lancaster, L., \& Pahl, K. Multimodality and Ethnography: Working at the Intersection. Qualitative Research 11 (2011) 227-237.

[22] Dourish, P. (1999). Evolution in the Adoption and Use of Collaborative Technologies. In: Proc. ECSCW 1999 Workshop on Evolving Use of Groupware.

[23] Dourish, P. The Appropriation of Interactive Technologies: Some Lessons from Placeless Documents. Computer Supported Cooperative Work 12:4 (2003) 465-490.

[24] Dourish, P. Re-space-ing place: "place" and "space" ten years on. In Proc. $C S C W^{\prime}$ '06. ACM Press, New York, NY, 2006, pp. 299-308.

[25] Eco, U. The Role of the Reader. Explorations in the semiotics of texts. Indiana University Press, Bloomington, IN, 1979.

[26] Eco, U., Rorty, R., Culler, J., Brooke-Rose, C., Collini, S. (Ed.) Interpretation and Overinterpretation. Cambridge University Press, Cambridge, UK, 1992. 
[27] Guillén-Nieto, V., \& Aleson-Carbonell, M. Serious games and learning effectiveness: The case of It's a Deal! Computers \& Education 58:1 (2012) 435-448.

[28] Hamlen, K.R. Children's choices and strategies in video games. Computers in Human Behavior 27 (2011) 532-539.

[29] Harmon, E. \& Mazmanian, M. Stories of the Smartphone in everyday discourse: conflict, tension \& instability. In Proc. CHI '13. ACM Press, New York, NY, 2013, 1051-1060.

[30] Hassenzahl, M. The Thing and I: Understanding the Relationship Between User and Product. In: Blythe, M.A., Overbeeke, K., Monk, A.F., Wright, P.C. (Eds.) Funology. From Usability to Enjoyment Kluwer Academic Publishers, New York, NY, 2005, pp. 31-42.

[31] Hodge, R. \& Kress, G. Social Semiotics. Polity Press, Cambridge, 1988.

[32] Horne-Moyer, H.L., Moyer, B.H., Messer, D.C., Messer, E.S. The use of electronic games in therapy: a Review with Clinical Implications. Curr. Psychiatry Rep 16 (2014).

[33] Isbister, K., Flanagan, M., \& Hash, C. Designing Games for Learning: Insights form Conversations with Developers. In: Proc. CHI '10. ACM Press, New York, NY, 2010, pp. 2041-2044.

[34] Jewitt, C. Multimodal Methods for Researching Digital Technologies. In: Price, S., Jewitt, C., \& Brown, B. The SAGE Handbook of Digital Technology Research. Sage, London, UK, 2013, pp. 250-265.

[35] Juul, J. The Open and the Closed: Games of Emergence and Games of Progression. Proceedings of Compuper Games and Digital Cultures Conference. Tampere University Press, Tampere, FI, 2002.

[36] Katmada, A., Mavridis, A., Tsiatsos, T. Implementing a Game for Supporting Learning in Mathematics. Electronic Journal of e-Learning 12:3 (2014) 230242.

[37] Kannabiran, G., Bardzell, J., Bardzell, S. I just made love: the system and the subject of experience. In CHI '12 EA. ACM Press, New York, NY, 2012, 5160 .

[38] Kress, G. Multimodality. A Social Semiotic Approach to Contemporary Communication. Routledge, New York, NY, 2010.

[39] Kress, G. 'Partnerships in Research': Multimodality and Ethnography. Qualitative Research 11 (2011) 239-260.

[40] Lemke, J. Multimodality, Identity, and Time. In Jewitt, C. (Ed.) The Routledge Handbook of Multimodal Analysis. Routledge, London, UK, 2009, pp.140150. 
[41] Lemke, J. (2013). Games and Learning: Diversifying Opportunity or Standardizing Advantage? Paper presented at AERA 2013 Annual Meeting. San Francisco, CA.

[42] Mitgutsch, K. \& Alvarado, N. Purposeful by Design? A Serious Design Game Design Assessment Framework. In: Proc. FDG '12. ACM Press, New York, NY, 2012, 121-128.

[43] Muratet, M., Delozanne, E., Torguet, P., \& Viallet, F. Serious game and students' learning motivation: effect of context using prog\&play. In Proc. ITS '12. Springer-Verlag, Berlin, D, 2012, 123-128.

[44] Nolan, J., McBride, M. Beyond gamification: reconceptualizing game-based learning in early childhood environments. Information, Communication \& Society 17:5 (2014) 594-608.

[45] Pareto, L., Arvemo, T., Dahl, Y., Haake, M., \& Gulz, A. A teachable-agent arithmetic game's effects on mathematics understanding, attitude and selfefficacy. In Biswas, G., Bull, S., Kay, J., Mitrovic, A. (Eds.) Artificial Intelligence in Education. Springer, Berlin Heidelberg, 2011, pp. 247-255.

[46] Rosenfeld Halverson, E. Participatory Media Spaces: A Design Perspective on Learning with Media and Technology in the Twenty-First Century. In:

Steinkuehler, C, Squire, K, Barab, S. (Eds.) Games, Learning, and Society. Cambridge University Press, New York, NY, 2012, pp. 244-268.

[47] Salovaara, A. Repurposive Appropriation and Creative Technology Use in Human-Computer Interaction. Unpublished doctoral dissertation, Helsinki Institute for Information Technology, Helsinki, FI, 2012.

[48] Satchell, C., Dourish, P. Beyond the User: Use and Non-Use in HCI. Proceedings of the 21st Annual Conference of the Australian ComputerHuman Interaction Special Interest Group (OzCHI '09). ACM Press, New York, NY, 2009, 9-16.

[49] Schrier, K. Using Digital Games to Teach History and Historical Thinking. In: Schrier, K. (Ed.) Learning, Education and Games. ETC Press, Pittsburgh, PA, USA, 2014, pp. 73-91.

[50] Sengers, P., Gaver, B. Staying open to interpretation: engaging multiple meanings in design and evaluation. Proc. DIS '06. ACM Press, New York, NY, 2006, 99-108.

[51] Squire, K. Designed Cultures. In: Steinkuehler, C, Squire, K, Barab, S. (Eds.) Games, Learning, and Society. Cambridge University Press, New York, NY, 2012, pp. 10-31.

[52] Squire, K. Video Games and Learning. Educational Researcher 35:8 (2006) 19-29. 
[53] Steinkuehler, C. Parenting and Videogames. Journal of Adolescent \& Adult Literacy. 59:4 (2016) 357-361.

[54] Stueber, Karsten R. "How to Think About Rules and Rule Following." Philosophy of the Social Sciences 35:3 (2005) 307-323.

[55] Suchman, L. A. Plans and Situated Actions: the Problem of Human-Machine Communication. Cambridge University Press, New York, NY, 1987.

[56] Turkay, S., Hoffman, D., Kinzer, C.K., Chantes, P., Vicari, C. Toward Understanding the Potential of Games for Learning: Learning Theory, Game Design Characteristics, and Situating Video Games in Classrooms. Computers in the Schools: Interdisciplinary Journal of Practice, Theory, and Applied Research. 31:1-2 (2014) 2-22.

[57] Van Leeuwen, T. Introducing Social Semiotics. Routledge, New York, NY, 2005.

[58] Vissers, J., De Bot, L., \& Zaman, B. MemoLine: evaluating long-term UX with children. In Proc. IDC '13. ACM Press, New York, NY, 2013, 285-288.

[59] Winn, B.M. The Design, Play and Experience Framework. In: Ferdig, R.E. (Ed.) Handbook of Research on Effective Electronic Gaming in Education. IGI Global, London, UK, 2009, pp. 1010-1024.

[60] Zhu, J., Foster, A., Muschio, G., Patterson, J.H., Valls-Vargas, J., Newman, D. Towards balancing learner autonomy and pedagogical process in educational games. In Proc. CHI PLAY' 14. ACM Press, New York, NY, USA, 2014, 455456. 


\section{APPENDIX A: MONKEY TALES DIARY}

\section{General Information}

Hello, this is the diary of <respondent name>.

I am ... years old.

I have ... brothers and ... sisters.

When I grow up, I would like to become ... .

My hobbies are: ...

At home, I have a:

PC, Playstation, Xbox, Wii, Nintendo DS, PSP / PS Vita, other

I play my favourite games on:

PC, Playstation, Xbox, Wii, Nintendo DS, PSP / PS Vita, other

How often do you play video games?

Every day, multiple times per week, weekly, monthly

\section{Game Sessions}

1. I just played Monkey Tales for <amount of time> .

2. Today's date:

3. Which levels did you play?

4. What was the most fun activity you did in Monkey Tales today? Why?

5. What was the least fun?

6. Why did you quit playing?

7. Did anyone help you? Who?

If so, why did you receive help?

8. In which part of the game world did you play?

9. Which games did you play against the monkey?

10. How many monkeys have you collected?

Word cloud: Circle the words in the word cloud that reflect how you felt while playing.

\begin{tabular}{|l|l|l|}
\hline Great & Cool & Tiresome \\
\hline Tired & Annoying & Enjoying \\
\hline Boring & Irritated & Angry \\
\hline Funny & Hard & I am good! \\
\hline Fun & Away from the world & Fascinating story \\
\hline
\end{tabular}

\section{Other Questions and Tasks}

Other questions and tasks, distributed in between the game sessions:

1. Paste a photograph of yourself.

2. Did you use the computer for other activities today? Which ones?

3. Where do you go to school?

4. What is the top 3 of your favourite school subjects?

5. Why are these your favourite subjects? 
6. Draw your favourite teacher.

7. If you could send one object away in a time machine, what would it be?

8. What are your hobbies? What do you really enjoy doing? Paste some pictures of your hobbies.

9. Paste a photograph of the places where you play Monkey Tales.

10. What is your favourite TV show? What is your favourite film?

11. Do you play other video games? What is your all-time favourite video game?

\section{APPENDIX B: INTERVIEW GUIDE}

\section{Parents}

1. Did you play the game yourself, as a parent?

Or did you only watch your children playing?

Why did you play the game? Because it was fun? Because you felt it was your responsability?

2. Did you encourage your child to play the game?

How long did your child normally play?

Did you sometimes tell your child to stop playing? Why?

What do you consider an appropriate length for playing the game?

What do you consider too long?

Are there specific rules concerning watching TV or playing video games?

3. Did you notice any frustration in your child's behaviour?

Why?

Were there game aspects that were difficult? Which ones?

4. Where did the child play the game most often?

How do games fit within the family, or between other hobbies?

How did Monkey Tales fit within the family, or between other hobbies, the past few weeks?

5. Which educational games do you own? Why?

6. Which educational games does your child play at school? Which ones at home?

7. Have you purchased educational games in the past?

8. Do you think educational games are useful?

\section{Children}

1. Had you ever played Monkey Tales before you received it for the test?

2. How did you like the game?

3. Did you like how the game looked? Was playing the game as fun as it looked beforehand?

4. How do you like your character in Monkey Tales? Was controlling the character easy or difficult?

5. Have you ever played other educational computer games before Monkey Tales?

6. Have you ever learned things from 'regular' games you buy in the store?

7. Did you play all levels in Monkey Tales? Did you finish the game?

8. Which aspects were very good in the game? 
9. Which aspects were very bad? What could be better in the game?

10 . Which was the coolest game you played against the monkey?

11 . Do you play any other computer games? Why?

12. Did you experience any computer issues playing Monkey Tales?

13. Do you have your own computer, or do you share it with the rest of the family? With your parents, or with your brothers or sisters?

\section{APPENDIX C: MEMOLINE SESSION}

\section{MemoLine}

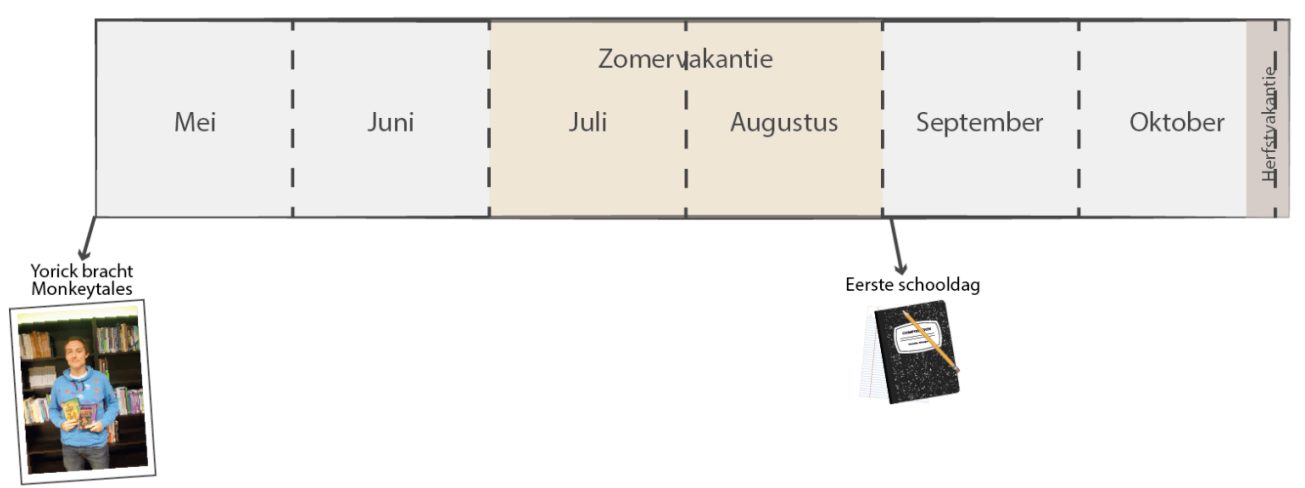

Figure C.1 Memoline timeline.

1. Was it clear or unclear to you what you should do in Monkey Tales, and how you should do it?

Green: I played Monkey Tales and it was clear to me what I should do in Monkey Tales, and how I should do it.

Red: I played Monkey Tales and it was clear to me what I should do in Monkey Tales, and how I should do it.

Gray: I did not play Monkey Tales any more.

2. Did you, or didn’t you enjoy playing Monkey Tales?

Green: I played Monkey Tales and I enjoyed it.

Red: I played Monkey Tales and I did not enjoy it.

Gray: I did not play Monkey Tales any more.

3. How challenging or easy did you think Monkey Tales was?

Green: I played Monkey Tales and I felt challenged while playing.

Red: I played Monkey Tales but I did not feel challenged while playing.

Gray: I did not play Monkey Tales any more.

4. How often did you play Monkey Tales?

Green: I often played Monkey Tales. 
Red: I sometimes played Monkey Tales.

Gray: I did not play Monkey Tales any more.

Word cloud: Circle the words in the word cloud that reflect how you feel about Monkey Tales now.

\begin{tabular}{|l|l|l|}
\hline Great & Cool & Tiresome \\
\hline Tired & Annoying & Enjoying \\
\hline Boring & Irritated & Angry \\
\hline Funny & Hard & I am good! \\
\hline Fun & Away from the world & Fascinating story \\
\hline
\end{tabular}

\section{Final Questionnaire / Interview}

1. How many levels did you play in total? How far did you get in the game? Did you finish the game more than once?

2. Which activity in Monkey Tales was the most fun? Why?

3. Which activity in Monkey Tales was the least fun? Why?

4. What do you think is still missing in Monkey Tales?

5. Why did you stop playing?

6. Do you play other games now? Which ones?

7. What do you think is more fun or less fun in Monkey Tales, compared to these other games? 